\title{
Vigilância da influenza: avanços e desafios para o Brasil
}

\author{
Divânia Dias da Silva França ${ }^{1}$ \\ Karlla Antonieta Amorim Caetano ${ }^{2}$ \\ Grécia Carolina Pessoni ${ }^{3}$ \\ Leandro Nascimento da Silva ${ }^{4}$ \\ Sheila de Arruda Santos Araújo ${ }^{5}$ \\ Adriana Magalhães da Silva ${ }^{6}$ \\ Laura Branquinho do Nascimento ${ }^{7}$ \\ Fluvia Pereira Amorim da Silva ${ }^{8}$
}

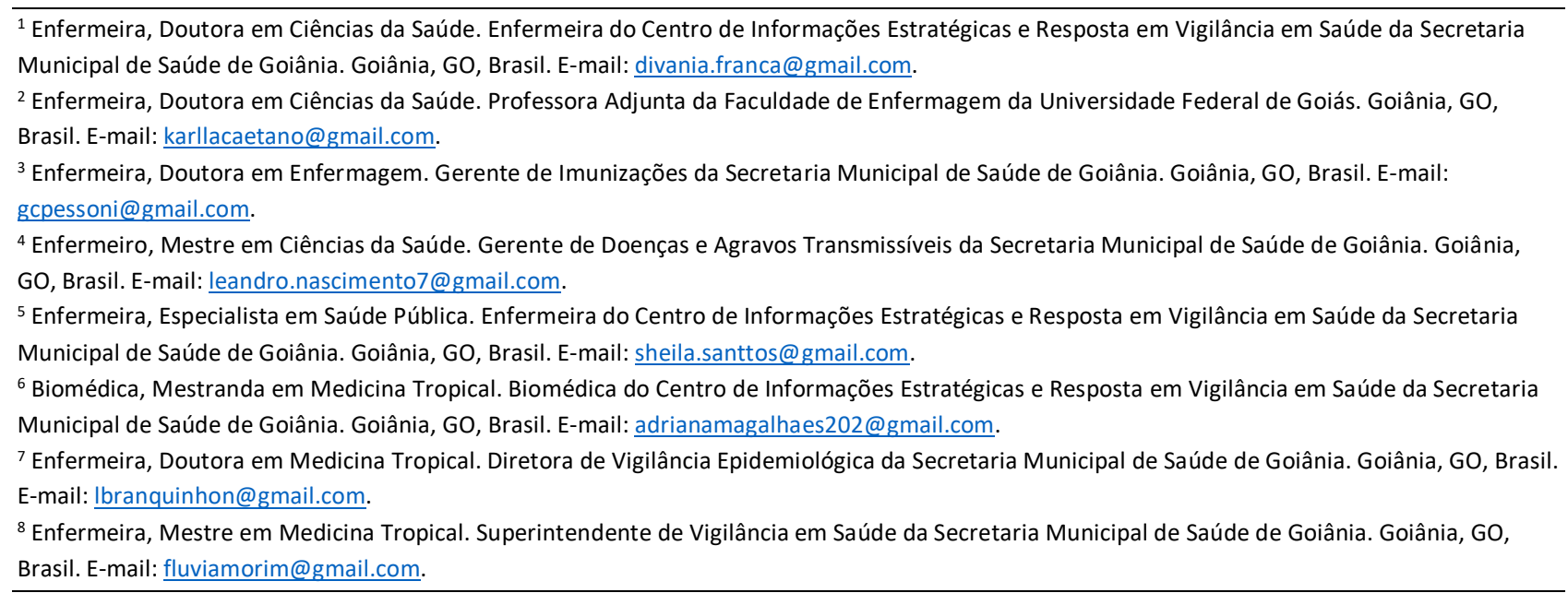

A infecção pelo vírus influenza causa uma doença viral aguda do trato respiratório, com distribuição global, tendência à sazonalidade e maior expressão nos períodos de outono e inverno ${ }^{(1)}$. Os vírus influenza pertencem à família Orthomyxoviridae, possuem genoma de RNA segmentado e basicamente quatro tipos virais catalogados, sendo eles: A, B, C e D. Os vírus influenza A e B possuem potencial epidêmico, sendo que o tipo A possui expressão pandêmica. O vírus tipo C é menos frequente e relacionado a infecções leves, portanto, sem grandes impactos na saúde pública. Já o vírus influenza D é exclusivamente zoonótico(2).

A Organização Mundial de Saúde (OMS) estima uma carga global de aproximadamente 3 a 5 milhões de casos graves por ano, destes, cerca de 290.000 a 650.000 pessoas morrem em decorrência de complicações respiratórias. Adicionalmente, as epidemias podem resultar em altos níveis de absenteísmo no trabalho/escola, perdas de produtividade e elevada sobrecarga dos serviços e trabalhadores de saúde ${ }^{(1)}$.

No Brasil, a vigilância epidemiológica da influenza iniciou em 2000 com o monitoramento dos casos de síndrome gripal em unidades de saúde sentinela ${ }^{(3)}$. Em 2004, após a ameaça da gripe aviária altamente patogênica, o país aderiu a uma estratégia internacional proposta pelo Centro de Controle e Prevenção de Doenças (CDC) com 
o objetivo de promover o fortalecimento da rede de diagnóstico laboratorial para detectar o vírus influenza com potencial emergente e sazonal ${ }^{(4)}$.

Estas iniciativas não foram capazes de minimizar os impactos deletérios da pandemia pelo vírus influenza A (H1N1)pdm09, que só em 2009, acometeu 50.482 pessoas em todo o país e provocou 2.060 óbitos ${ }^{(5)}$. Entretanto, a presente situação funcionou como um grande laboratório para avaliar e aprimorar a rede nacional de vigilância e assistência relacionada a esse agravo. O monitoramento atual, além de identificar os vírus respiratórios circulantes no Brasil, colabora na adequação da vacina de influenza sazonal para o Hemisfério Sul, garantindo a representatividade mínima da circulação viral em todas as unidades federadas do país ${ }^{(6)}$.

Dados do Ministério da Saúde do Brasil, entre 2012 e 2017, mostram uma redução no número de casos por influenza quando comparados com a pandemia ocorrida em 2009. Neste período, 27.674 indivíduos foram identificados com o vírus influenza e 4.605 óbitos foram associados à infecção. Por outro lado, de janeiro a junho de 2018 (semana epidemiológica 25), 3.558 casos foram confirmados por influenza no país. Goiás concentrou cerca de $10,4 \%$ e $63,0 \%$ do total de casos registrados no Brasil e região Centro-Oeste, respectivamente, apresentando uma taxa de letalidade $18,0 \%{ }^{(7)}$.

Epidemiologicamente, sabe-se que as principais medidas de prevenção e controle da doença incluem a vacinação anual contra influenza, adoção das medidas de precaução padrão e para gotículas e introdução precoce de terapia medicamentosa para indivíduos com síndrome gripal, classificados como grupos de risco ${ }^{(8)}$.

Invariavelmente, a vacinação mostra-se como uma das medidas mais efetivas para a prevenção de casos graves e a diminuição da letalidade ${ }^{(9)}$. Em contrapartida, a discussão sobre o período de disponibilização para o Hemisfério Sul da vacina é controverso. Pesquisadores ${ }^{(10-11)}$ destacam como adequado o início da vacinação em abril, prevendo que o maior risco de infecção por influenza na América do Sul, concentra-se entre os meses de abril a setembro. Entretanto, não há padrão sazonal para a ocorrência de influenza e outras doenças respiratórias no país. Há evidências de que na região Nordeste a imunização contra influenza tem sido realizada após o período de maior circulação do vírus(12).

De fato, ao se observar os últimos anos desta infecção no Brasil (2009-2018), verifica-se que entre os meses de janeiro à março não há distribuição uniforme do agravo em todas as regiões do Brasil, apesar de a vacina contra influenza ter sido distribuída rotineiramente entre abril e maio em todo país. Em 2017, nas Regiões Nordeste e Norte o número de casos notificados antes da campanha nacional de vacinação contra influenza foi maior em comparação aos meses subsequentes. Além disso, na Região Centro-Oeste o pico de casos identificados também antecedeu a campanha nacional(7).

A partir deste cenário, questiona-se quais medidas poderiam ser tomadas por parte da vigilância em saúde no Brasil que fossem capazes de minimizar a morbimortalidade por esta síndrome. Resultados de uma pesquisa(13) apontam como uma estratégia viável para o Brasil a implementação da vacinação pelo menos três meses antes do que é recomendado atualmente. Outra opção, seria a implementação de um cronograma diferenciado que antecipasse a vacinação para algumas regiões, considerando a situação epidemiológica local. No entanto, a antecipação da vacina envolve um grande desafio logístico para laboratórios internacionais e nacionais. Assim, deve-se investigar e estimular a viabilidade da introdução antecipada da vacina no Brasil. 
Um outro fator que deve ser levado em consideração durante os períodos de maior expressão deste agravo é o modo indiscriminado da veiculação de informação por parte da mídia e redes sociais, que em proporções distorcidas, nem sempre refletem a situação epidemiológica real. Tais mecanismos levam a uma grande repercussão no comportamento da população em geral e profissionais de saúde, causando uma alta demanda pela vacina e, por vezes, a comercialização na rede privada com valores exorbitantes e com qualidade técnica questionável. Isso ocorre em razão de que as condutas para acondicionamento, transporte e administração da vacina nem sempre seguem as especificações preconizadas por órgãos oficiais. Essa situação pode reduzir a eficácia do imunobiológico, além de causar eventos adversos relacionados à vacinação.

Os fatos apresentados não deixam dúvidas que outras epidemias sazonais associadas ao vírus influenza poderão atingir o Brasil em um futuro próximo. Esforços nacionais para a redução da letalidade deste agravo devem ser prioridade para a saúde pública. A mobilização dos pesquisadores, diante das lacunas de conhecimento, seja a respeito da disponibilização da vacina contra influenza, como também da consequência da informação/comunicação sem responsabilidade em momentos de crises, é determinante para o enfrentamento da influenza no Brasil.

\section{REFERÊNCIAS}

1. World Health Organization. Influenza (Seasonal) [Internet]. Genebra (SU): World Health Organization; 31 jan. 2018 [acesso em: 20 jul. 2018]. Disponível em: http://www.who.int/mediacentre/factsheets/fs211/en/.

2. International Committee on Taxonomy of Viruses. Taxonomy [Internet]. [Lugar desconhecido]: International Committee on Taxonomy of Viruses; c2017 [acesso em: 20 jul. 2018]. Disponível em: https://talk.ictvonline.org/taxonomy/.

3. Barros FR, Daufenbach LZ, Vicente MG, Soares MS, Siqueira M, Carmo EH. O desafio da influenza: epidemiologia e organização da vigilância no Brasil. Boletim eletrônico epidemiológico [Internet]. 2004 [acesso em: 20 jul. 2018];4(1):1-7. Disponível em:

http://bvsms.saude.gov.br/bvs/periodicos/boletim eletronico epi ano04 n01.pdf.

4. Polansky LS, Outin-Blenman S, Moen AC. Improved Global Capacity for Influenza Surveillance. Emerg Infect Dis. [Internet]. 2016 [acesso em: 20 jul. 2018];22(6):993-1001. Disponível em: https://doi.org/10.3201/eid.2206.151521.

5. Ministério da Saúde, Secretaria de Vigilância em Saúde. Informe técnico de influenza [Internet]. Brasília: Ministério da Saúde; 2012 [acesso em: 20 jul. 2018]. Disponível em: http://portalarquivos2.saude.gov.br/images/pdf/2014/maio/22/informe-influenza2009-2010-2011-220514.pdf.

6. Ministério da Saúde. Guia para a Rede Laboratorial de Vigilância de Influenza no Brasil [Internet]. Brasília: Ministério da Saúde, 2016 [acesso em: 20 jul. 2018]. Disponível em:

http://bvsms.saude.gov.br/bvs/publicacoes/guia laboratorial influenza vigilancia influenza brasil.pdf.

7. Ministério da Saúde. Influenza/Gripe. Situação Epidemiológica / Dados [Internet]. Brasília (BR): Ministério da Saúde; c2013-2018 [acesso em: 20 jul. 2018]. Disponível em: http://portalms.saude.gov.br/saude-de-a-z/gripe/situacao-epidemiologica-dados. 8. Srivastav A, Santibanez TA, Lu PJ, Stringer MC, Dever JA, Bostwick M, et al. Preventive behaviors adults report using to avoid catching or spreading influenza, United States, 2015-16 influenza season. PLoS One [Internet]. 2018 [acesso em: 20 jul. 2018];13(3):e0195085. Diponível em: https://doi.org/10.1371/journal.pone.0195085.

9. Demicheli V, Jefferson T, Di Pietrantonj C, Ferroni E, Thorning S, Thomas RE, et al. Vaccines for preventing influenza in the elderly. Cochrane Database Syst Rev [Internet]. 2018 [acesso em: 20 jul. 2018];(2):CD004876. Disponível em:

https://doi.org/10.1002/14651858.CD004876.pub4.

10. Durand LO, Cheng PY, Palekar R, Clara W, Jara J, Cerpa M, et al. Timing of influenza epidemics and vaccines in the American tropics, 2002-2008, 2011-2014. Influenza Other Respir Viruses [Internet]. 2016 [acesso em: 20 jul. 2018];10(3):170-5. Disponível em: https://doi.org/10.1111/irv.12371.

11. Freitas ARR, Donalisio MR. Excess of Mortality in Adults and Elderly and Circulation of Subtypes of Influenza Virus in Southern Brazil. Front Immunol [Internet]. 2018 [acesso em: 20 jul. 2018];8;8:1903. Disponível em:

https://doi.org/10.3389/fimmu.2017.01903.

12. Raboni SM, Moura FEA, Caetano BC, Avanzi VM, Pereira LA, Nogueira MB, et al. Global Influenza Hospital-based Surveillance Network (GIHSN): results of surveillance of influenza and other respiratory viruses in hospitalised patients in Brazil, 2015. BMJ Open [Internet]. 2018 [acesso em: 20 jul. 2018];8(2):e017603. Disponível em: https://doi.org/10.1136/bmjopen-2017-017603. 
13. Mello WA, Paiva TM, Ishida MA, Benega MA, Santos MC, Viboud C, et al. The dilemma of influenza vaccine recommendations when applied to the tropics: the Brazilian case examined under alternative scenarios. PLoS One [Internet]. 2009 [acesso em: 20 jul. 2018];4(4):e5095. Disponível em: https://doi.org/10.1371/journal.pone.0005095.

\section{Como citar esse artigo:}

França DDS, Caetano KAA, Pessoni GC, Silva LN, Araújo SAS, Silva AM, et al. Vigilância da influenza: avanços e desafios para o Brasil. Rev. Eletr. Enf. [Internet]. 2018 [acesso em: ];20:v20a00. Disponível em: https://doi.org/10.5216/ree.v20.53937. 